
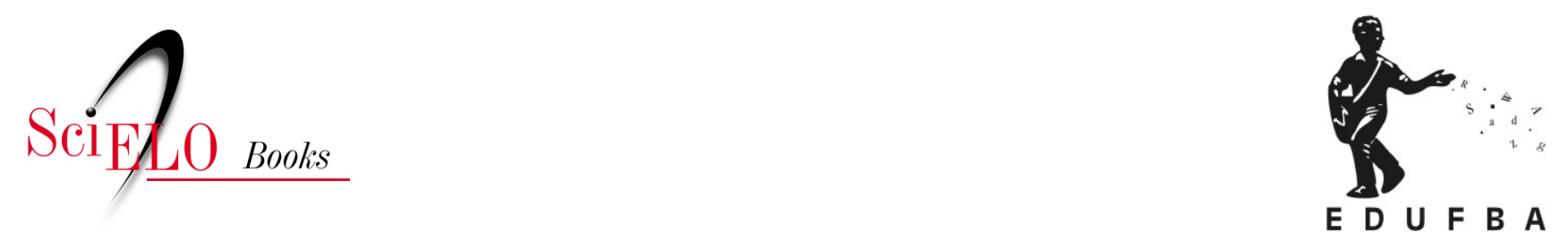

\title{
A hipótese da agenda-setting e a teoria do newsmaking no Blog do Noblat
}

Allysson Viana Martins

\section{SciELO Books / SciELO Livros / SciELO Libros}

MARTINS, A.V. A hipótese da agenda-setting e a teoria do newsmaking no Blog do Noblat. In:

RIBEIRO, J.C., FALCÃO, T., and SILVA, T. orgs. Midias sociais: saberes e representações [online]. Salvador: EDUFBA, 2012, pp. 271-287. ISBN 978-85-232-1734-1. Availablefrom: doi:

10.7476/9788523217341.015. Also available in ePUB from:

http://books.scielo.org/id/hcmrr/epub/ribeiro-9788523217341.epub

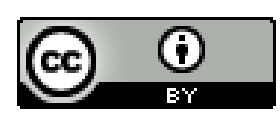

All the contents of this work, except where otherwise noted, is licensed under a Creative Commons Attribution 4.0 International license.

Todo o conteúdo deste trabalho, exceto quando houver ressalva, é publicado sob a licença Creative Commons Atribição 4.0.

Todo el contenido de esta obra, excepto donde se indique lo contrario, está bajo licencia de la licencia Creative Commons Reconocimento 4.0. 


\section{A hipótese da agenda-setting e a teoria do newsmaking no Blog do Noblat}

Allysson Viana Martins

Introdução

O jornalismo produzido na web pode ser encontrado em sites, portais e blogs, entre outros espaços. Os blogs modificam o modo de produção do webjornalismo, na medida em que mesclam suas especificidades com as particularidades do fazer jornalístico. Esse hibridismo é tão evidente que o pesquisador Marcelo Träsel (2009, p. 101) defende que existe uma "bloguização" dos (web)jornais e uma "jornalistização" dos blogs. Com essa inter-relação em perspectiva, observamos a rotina de produção no Blog do Noblat por meio da teoria do newsmaking. O pesquisador português Jorge Pedro Sousa (2000) aposta que esta teoria pode ser considerada uma teoria geral da notícia, portanto, aplicada em qualquer meio produtor de jornalismo, sem esquecer, contudo, de que cada veículo traz uma rotina diferente. (LAGE, 2006; PENA, 2008) Outra questão intrigante para nosso estudo é o papel que os blogs desempenham no processo de agendamento midiático, conforme já previa Takeshita (2006), ou de agenda intermídia. (LOPEZ-ESCOBAR et al. 1998; McCOMBS, 2005)

Esses dois conceitos são aqui estudados pela perspectiva de Mauro Wolf (2005, p. 137), compreendo o que o autor chama de "[...] tendências atuais da communication research" A hipótese da agendasetting e a teoria do newsmaking representam uma ruptura na pesquisa 
em comunicação, passando de um entendimento dos efeitos a curto prazo para os efeitos a longo prazo. Nas palavras de Wolf (2005, p. 138), "conquistou-se a consciência de que as comunicações não intervêm diretamente no comportamento explícito; de preferência, tendem a influenciar o modo como o destinatário organiza a própria imagem do ambiente".

\section{Blog do Noblat}

"Bem-vindos ao meu blog". Foi com essa mensagem que o jornalista Ricardo Noblat iniciou seu blog ${ }^{1}$ em 20 de março de 2004, enquanto mantinha uma coluna no jornal $O$ Dia. O jornalista sempre utilizou o dispositivo para auxiliá-lo de alguma maneira em sua profissão, enfatizando ainda mais a relação entre blog e jornalismo. Isso se dava a tal ponto que, quando parou de escrever no $\mathrm{O} \mathrm{Dia}$, Noblat afirmou que iria desfazer-se do seu blog, ou ao menos diminuir drasticamente a assiduidade das postagens, já que precisava dos outros meios para ganhar dinheiro. Todavia, por causa dos pedidos dos leitores e da ausência de afazeres, continuou com o blog, sem saber que um ano mais tarde (em 2005) seria contratado pelo $I G$, transferindo seu dispositivo para o portal. Desde então, Noblat percebeu que poderia se sustentar não apenas com as outras mídias, mas também por meio do seu blog. Ainda em 2005, o UOL e o Estado de S. Paulo disputaram o blogueiro, sendo o último o escolhido por ele. Dois anos depois, em 2007, o Blog do Noblat é transferido para o portal $O$ Globo, onde se encontra até hoje.

Já faz algum tempo que Noblat é um dos mais renomados blogueiros brasileiros, principalmente entre os blogs com caráter jornalístico. Considerado um especialista em política - embora trate de outros temas -, o jornalista consolidou essa imagem, bem como a quantidade de leitores, devido ao seu oportunismo ao analisar e ao comentar es-

$<$ http://oglobo.globo.com/pais/noblat/> 
cândalos do universo político - aliado também à sua trajetória profissional. No início do blog, Noblat já havia chamado atenção por trazer à tona um fato que não havia sido comentado em nenhuma grande mídia: o desrespeito do presidente Lula à Constituição. ${ }^{2}$

Como já tinha certo prestígio com as fontes, os profissionais da área, as empresas da mídia e alguns leitores, antes de ingressar na blogosfera, Ricardo Noblat não só manteve a reputação adquirida ao longo dos anos como ampliou a gama de leitores, chamando cada vez mais atenção e tornando seu blog um ponto de referência. Talvez o momento mais importante tenha sido quando o mensalão de 2005 circulava em toda mídia, conforme declarou em entrevista ao Programa do Jô, em 10 de setembro de 2008. Como era reconhecido como um jornalista especializado em política - graças aos seus trabalhos anteriores -, a cobertura do tema em seu blog fez com que Noblat atraísse quase todos os navegantes que o acompanham até hoje.

Ainda que seja mais conhecido por essas coberturas políticas, não podemos afirmar que o Blog do Noblat só veicule notícias dessa área e que seus leitores só se interessem por ela. Em março de 2005, por exemplo, o jornalista divulga a notícia de que Chico Buarque estava em companhia de uma mulher casada, e seu blog tem 51 mil visitantes únicos absorvendo a informação. Apesar desse fato, política é o que impera no blog e é o que os leitores mais procuram, tanto que, quando Noblat fez cobertura em tempo real do depoimento do deflagrador do mensalão, Roberto Jefferson, o dispositivo, em 24 horas, teve mais de 100 mil navegantes únicos. $\mathrm{O}$ assunto rendeu, ao fim do mês, 2 milhões de visitas ao blog.

O pesquisador Alex Primo (2008a, 2008b) tipifica os blogs em dois grandes grupos, que têm outras subdivisões: individuais (onde encontramos os blogs pessoais e os profissionais) e coletivos (no qual

Quando o excessivo consumo de álcool do presidente foi parar no The New York Times, Lula mandou suspender o visto do representante do jornal no Brasil, expulsando-o. Na ocasião, Lula teria dito: "Foda-se a Constituição". 
estão inseridos os grupais e os organizacionais). De acordo com sua categorização, o autor considera o Blog do Noblat como organizacional, pois é produzido por uma pequena equipe, não apenas pelo jornalista - como antes -, e tem um caráter quase empresarial, tentando manter o todo coeso através de algumas normas e de uma linha editorial, explícita ou não.

O corpus de nosso estudo compreendeu o início de março de 2010 - os dias 2, 3 e 4 -, correspondendo exatamente ao meio da semana (terça, quarta e quinta), porque acreditamos que a rotina não devia ser modificada, como acontece nos finais de semana de qualquer redação, a não ser que ocorra um fato extraordinário, como no último dia de análise. Além do mais, excluímos segunda e sexta por serem próximos aos dias em que a rotina é modificada, e porque ficaria um material bastante extenso para ser examinado, tendo em vista que o Blog do Noblat teve, em média, 46 postagens por dia.

Embora tenhamos selecionado três dias de análise correspondente ao meio da semana por pensarmos que a rotina não seria modificada, isso não foi o que ocorreu, haja vista que houve o julgamento para a manutenção de José Roberto Arruda, ex-prefeito de Brasília, na prisão. Portanto, no último dia de observação ( 4 de março, quinta-feira), o blog teve 57 atualizações, enquanto nos dois primeiros dias teve 42 e 40, respectivamente. Esse número elevado se deve ao fato de Severino Motta ter feito a cobertura da votação, veiculando voto a voto a escolha dos ministros.

Como o Blog do Noblat está contido no site Globo.com, da empresa Rede Globo - o conglomerado de mídia mais influente no Brasil -, pressupomos que o agendamento intermídia deve ocorrer com alta intensidade, tendo os jornais já renomados como fontes mais utilizadas. Embora seja um espaço coletivo, o Blog do Noblat recebe o nome do jornalista Ricardo Noblat. Desta forma, apostamos que ele deve ser o principal produtor em seu blog, com maior número de postagens, seja no que se refere às notícias copiadas ou às originais. Ainda 
que o blog transporte incialmente a ideia de um espaço para livre opinião, deve trazer outra visão, pois é um lugar no qual se produz jornalismo, logo, onde não só a opinião é privilegiada, mas também a informação e a interpretação dos fatos.

\section{A hipótese da agenda-setting ou do agendamento midiático}

A hipótese da agenda-setting parte do pressuposto de que os meios de comunicação de massa possuem certa capacidade em determinar as pautas públicas a partir daquilo que veiculam. (McCOMBS; SHAW, 1972) Os pesquisadores McCombs e Shaw, desenvolvedores da hipótese, baseiam-se em pesquisas anteriores para formular o conceito de agendamento midiático. Os autores citam Cohen, para quem a mídia fracassa em dizer às pessoas sobre como pensar, mas assustadoramente pode dizer ao público sobre o que pensar. Fazem referência também a Lang e Lang, que acreditam que os mass media forçam a atenção do público para assuntos determinados, além de construir a imagem de personalidades políticas. Em estudos posteriores, contudo, McCombs e outros (2000, p. 78) afirmam que é competência da mídia dizer "não só sobre o que pensar, mas como pensar sobre isso". Segundo Michael Mazarr (2007), a agenda-setting explica como, por que e onde ideias específicas se tornam ações. $\mathrm{O}$ autor cita John Kingdon, que utiliza o agendamento para entender "como aquela ideia veio à tona?".

$\mathrm{O}$ termo agenda-setting "[...] se refere à ideia de que em dado momento há uma hierarquia de assuntos aos quais se deve prestar atenção, mesmo quando se compete sobre o conteúdo futuro dessa hierarquia. Uma agenda é, portanto, um fenômeno estrutural que constrange os atores em um dado momento."3 (GREEN-PEDERSEN; MORTENSEN, 2010, p. 260). Para Wolf (2005, p. 143), a

3 Tradução nossa: "refers to the idea that at a certain point in time there is a hierarchy of issues, to which the relevant actors must pay attention even as they compete about the future content of 
hipótese da agenda-setting "não sustenta que a mídia tenta persuadir [...]. Descrevendo e precisando a realidade externa, a mídia apresenta ao público uma lista de fatos a respeito dos quais se pode ter uma opinião e discutir", por conseguinte, "a compreensão das pessoas em relação à grande parte da realidade social é modificada pelos meios de comunicação de massa”.

Uma das críticas de Takeshita (2006) é de que os efeitos no processo de agendamento são interpretados como uma resposta quase irracional, mecânica, baseada na aprendizagem da mídia. Para reforçar a ideia, o estudioso defende que muitos pesquisadores de agendasetting descrevem o processo de definição de agenda apenas como a transferência da importância da mídia para o público. Voltando seu pensamento para a situação atual da comunicação, Toshio Takeshita (2006) afirma que não está claro o quanto a internet tem realmente diversificado o conteúdo de notícias, e que a maioria dos seus usuários acessa um número limitado de sites de notícias.

Em nosso estudo, interessa indagar: "who sets the media agenda?" (LOPEZ-ESCOBAR et al., 1998). Entre os principais pontos que podem explicar a formação dessa agenda está a influência dos meios de comunicação, estudada como agenda intermídia. Este tipo de estudo começou através da influência das agendas nacionais de notícia nos jornais diários. Posteriormente, verificou-se a interferência da agenda dos grandes jornais impressos nas redes de televisão. Em meados de 1998, conforme falam Lopez-Escobar e outros (1998), a pesquisa sobre intermídia se focava em como as propagandas políticas influenciavam a agenda política nas mídias noticiosas. $\mathrm{O}$ poeta Dick Higino concebeu o termo intermedia como uma categoria formal para definir uma inter-relação entre diferentes meios que se fundem conceitualmente em uma nova mídia.

this hierarchy (e.g., Dearing \& Rogers 1996: 1-3). An agenda is thus a structural phenomenon in the sense that it constrains the relevant actors at any given time". 
McCombs (2005) definiu a interação entre os próprios veículos concorrentes como intermedia agenda-setting. Em pesquisas atuais, outro estudo que contribui diretamente para o nosso trabalho é o de Deva Woodly (2008). A autora aposta no blog como uma peça importante na atual conjuntura da comunicação política, pois seus usuários costumam colocar outras fontes, além das oficiais, e as divulgam abertamente. Woodly (2008) acredita que os blogs suprem deficiências das mídias tradicionais, como não dar voz às várias fontes existentes. Essa visão vai de encontro a nossa, quando defendemos que o Blog do Noblat não traz tantas diferenças em comparação com um meio tradicional, graças ao contexto em que está inserido, como já explicado.

\section{A teoria do newsmaking ou da rotina produtiva}

A teoria do newsmaking é considerada uma atualização e complementação da teoria do gatekeeper - que busca compreender os critérios de noticiabilidade -, pois procura entender todo o processo de rotina (diária, semanal, mensal ou mesmo de atualização constante) de produção da notícia, não só (mas também) os critérios que levaram a notícia a ser veiculada (inserida no estudo do gatekeeper). Dessa maneira, a função do gatekeeper estaria contida no processo de rotina, tendo em vista que

a intuição jornalística não é uma capacidade misteriosa de determinar notícias, mas sim uma capacidade rotineira [...] e praticada ao abrigo de parâmetros identificáveis (os valores-notícias, por exemplo), uma capacidade de combinar instantaneamente num ponto de equilíbrio fatores em si diversos. (WOLF 1985, apud SOUSA, 2000, p. 113)

Essa rotina de produção é geralmente dividida em três etapas e, embora não haja consenso quanto à nomenclatura de cada estágio, elas se referem ao mesmo processo. Em contrapartida aos três pontos 
que discorreremos abaixo, o pesquisador Mike Ward (2006, p. 1718) defende que o processo jornalístico deve ser descrito em quatro momentos: identificar; obter; selecionar; ordenar ou apresentar. A diferença entre Ward e outros autores é o acréscimo do "identificar". Os que defendem apenas três etapas o fazem, possivelmente, porque a fase de identificação não pode ser percebida por aqueles que fazem a análise a partir do produto final, mas somente por quem estiver acompanhando de dentro da redação o processo de construção da notícia.

Pesquisadores como Mario Erbolato e Mauro Wolf (2005, p. 229) falam de apenas três momentos: captação, redação, edição (ERBOLATO, 2006); e coleta, seleção, apresentação. (WOLF, 2005, p. 229) A denominação de Erbolato nos satisfaz mais por causa do termo "seleção", usado por Wolf. O estudioso Mike Ward (2006, p. 63) esclarece que "denominar uma etapa de seleção poderia dar a falsa impressão de que ela é parte de uma sequência”. Por conseguinte, para uma conceituação menos ambígua, utilizamos a nomenclatu-

278 ra do pesquisador brasileiro Mario Erbolato. Cumpre entender, no entanto, que "as análises sobre o newsmaking descrevem o trabalho de comunicação dos emissores como um processo que 'contém de tudo"”. (WOLF, 2005, p. 267)

No período de captação, verificamos: quem escreveu a postagem - haja vista que nosso objeto de estudo é um espaço coletivo; se o conteúdo é copiado ou original; quais fontes foram as mais utilizadas e de que meios de comunicação elas advêm - referindo-se às postagens copiadas, que são as fontes em sentido estrito. Neste momento, a hipótese da agenda-setting será evidenciada, pois perceberemos com qual intensidade o Blog do Noblat sofre um agendamento intermídia.

$\mathrm{Na}$ fase de redação, observamos os gêneros das notícias. Para Erbolato (2006, p. 30), o gênero jornalístico pode "ser dividido em quatro categorias: informativo, interpretativo, opinativo e diversional"; já a autora Cremilda Medina (1988, p. 70) explica que este último é apenas 
uma característica (de transformar a notícia em entretenimento ${ }^{4}$ ) que se dilui nos três tipos de estrutura discursiva: informação, interpretação e opinião - ou como a autora acha mais adequado: informação; informação ampliada; opinião. O primeiro é caracterizado pela superficialidade, pelo tratamento imediato e sem detalhamento. $\mathrm{O}$ jornalismo interpretativo é uma cobertura mais completa do fato, refletindo sobre suas consequências em vários âmbitos e o contextualizando melhor. O último estilo (opinativo) é especificado por um comentário do jornalista, revelando explicitamente sua opinião ou da empresa.

$\mathrm{Na}$ fase de edição, examinamos em qual editoria a postagem se encaixa e os formatos midiáticos utilizados. Para isso, definimos dez editorias mutuamente excludentes, embora saibamos que um assunto pode ser interdisciplinar: 1) Arte/Cultura. 2) Ciência/Educação. 3) Comportamento/Coluna. 4) Classificados/Propaganda. 5) Esporte. 6) Economia. 7) Informática/Tecnologia. 8) Policial. 9) Política. 10) Social/Serviço. Quanto aos formatos midiáticos, verificamos qual é o mais requisitado: áudio, imagem, infográfico-animação, vídeo, texto ou link.

\section{Agendamento e rotina no Blog do Noblat}

Das 139 postagens analisadas, $69(49,6 \%)$ são originais e 70 $(50,3 \%)$ copiadas, existindo, por conseguinte, um equilíbrio entre o que advém de outro meio e o que é produzido por Noblat e seus colaboradores, sobretudo Severino Motta. Dos 139 materiais, Severino Motta e Ricardo Noblat foram responsáveis por 122, isto fica em torno de $87,8 \%$ de todo conteúdo disponibilizado. Enquanto Ricardo Noblat abasteceu (nos dias que estudamos) 60,4\% do blog - equiva-

\footnotetext{
Sousa (2000, p. 93) também disserta sobre o assunto em consonância com Medina: "De fato, hoje as notícias e o entretenimento competem pela audiência. Por isso, as notícias têm-se, gradualmente, tornado infotainment. As notícias são vistas cada vez mais como um produto de consumo e menos como um bem social, o que é perigoso".
} 
lente a 84 postagens -, Severino Motta publicou 38 matérias, o que dá $27,3 \%$ do material dos três dias de pesquisa.

Ainda que Noblat produza mais que o dobro do seu principal colaborador, o conteúdo veiculado por ele é, em grande maioria, copiado de outro meio. Apesar de distribuir menos da metade do conteúdo do dono do blog, Severino Motta produz quase o dobro de conteúdo original a mais que Noblat (ver Tabela 1). No período estudado, o Blog do Noblat teve 69 postagens de caráter original, das quais 34 $(49,3 \%)$, praticamente a metade, foram de responsabilidade de Severino Motta, enquanto Ricardo Noblat produziu apenas 18 (26,1\%), sendo o restante das outras matérias originais elaboradas pelos outros colaboradores. Os conteúdos copiados, por sua vez, foram expostos só por Noblat e Motta. Entretanto, os números possuem diferenças enormes. Apenas 5,7\% (4) das postagens copiadas foram realizadas por Severino Motta, enquanto Ricardo Noblat efetuou 94,3\% (66).

Tabela 1 - Postagens de Ricardo Noblat e Severino Motta.

\begin{tabular}{|l|l|l|l|}
\hline & RICARDO NOBLAT & SEVERINO MOTTA & TOTAL \\
\hline ORIGINAL & $18(26,1 \%)$ de 69 & $34(49,3 \%)$ de 69 & $52(75,4 \%)$ de 69 \\
COPIADA & $66(94,3 \%)$ de 70 & $4(5,7 \%)$ de 70 & $70(100 \%)$ de 70 \\
TOTAL & $84(60,4 \%)$ de 139 & $38(27,3 \%)$ de 139 & $122(87,8 \%)$ de 139 \\
\hline
\end{tabular}

Cumpre destacar novamente que, das 139 postagens analisadas, 70 (50,3\%) foram copiadas e, através delas, são percebidas várias fontes, ainda que haja a predominância de algumas. $\mathrm{O}$ agendamento dos meios de comunicação tradicionais sobre o Blog do Noblat fica evidente quando observamos que $O$ Globo $(51,4 \%)$, por exemplo, possui mais da metade das referências, acompanhado de outras grandes empresas de comunicação, como Folha (11,4\%) e Estadão (11,4\%). Existe, deste modo, uma preferência pelas empresas consolidadas, com mais renome e credibilidade. Além do mais, há uma supervalori- 
zação da empresa em que o blogueiro trabalha, a Rede Globo, podendo ser percebida pela referência constante à versão on-line do jornal O Globo (ver Tabela 2). Como Noblat utiliza o jornal como principal fonte de veiculação de informação, isso ajuda a divulgar tanto o seu blog quanto a empresa com a qual tem vínculo, haja vista que seus seguidores, vez ou outra, acessam o site $O$ Globo, sobretudo porque no Blog do Noblat existe o hábito de dispor links para as matérias que foram copiadas.

Tabela 2 - Fontes das 70 postagens copiadas.

\begin{tabular}{|c|c|c|c|}
\hline O GLOBO & $36(51,4 \%)$ & FOLHA & $8(11,4 \%)$ \\
\hline ESTADÃO & $8(11,4 \%)$ & SITE AVULSO & $4(5,7 \%)$ \\
\hline BLOG & $3(4,3 \%)$ & Correio Braziliense & $3(4,3 \%)$ \\
\hline BBC & $2(2,9 \%)$ & GAZETA & $2(2,9 \%)$ \\
\hline Estado de Minas & $1(1,4 \%)$ & ASSESSORIA & $1(1,4 \%)$ \\
\hline G1 & $1(1,4 \%)$ & Sem Referência & $1(1,4 \%)$ \\
\hline
\end{tabular}

No estudo dos gêneros, foram analisadas nas postagens apenas o que o Blog do Noblat publicou. Portanto, uma matéria copiada pode ser considerada informativa no blog, embora seja um produto interpretativo no espaço original. Essa percepção se deve ao fato de que Noblat (ou algum colaborador) pode ter copiado apenas os dois primeiros parágrafos, transformando a matéria em informativa, ainda que coloque o link ao final para o conteúdo original, que é interpretativo.

No que se refere aos gêneros (verTabela 3), dentre as 139 postagens examinadas, 93 (66,9\%) eram informativas, 17 (12,2\%) interpretativas e 29 (20,8\%) opinativas. À primeira vista, baseado nos números, poderíamos dizer que há algumas contradições, pois um blog é um espaço de opinião, no qual o blogueiro expõe seu pensamento, sua visão e sua argumentação acerca de alguns assuntos e fatos, principalmente quando o dispositivo tem o nome do dono/administrador. Todavia, 
isso não acontece no Blog do Noblat. A experiência que o jornalista tem com o dispositivo parece ser o de um meio para informar seus leitores, no qual faz um apanhado de notícias (devido ao alto número de matérias copiadas que o jornalista disponibiliza - ver Tabela 1), e não onde expõe seu ponto de vista sobre algumas situações.

Ainda assim, apostar no argumento do blog como um espaço opinativo é crer que os dispositivos da blogosfera podem ser apenas diários na web, sem enxergar as múltiplas possibilidades de apropriação que se pode fazer. Alex Primo (2008a; 2008a), como já explicado, defende há algum tempo a categorização do blog em dois grupos, que se subdividem. Os individuais: pessoal e profissional; e os coletivos: grupais e organizacionais. O pesquisador situa o Blog do Noblat entre os organizacionais, ou seja, aqueles supridos de conteúdo por mais de um usuário e que possuem algumas características institucionais. Portanto, a não predominância do gênero opinativo não deve ser encarada como um paradoxo, pois o blogueiro usa seu dispositivo como mais lhe interessa.

Tabela 3 - Gêneros jornalísticos nas postagens.

\begin{tabular}{|c|c|}
\hline INFORMATIVO & $93(66,9 \%)$ \\
\hline INTERPRETATIVO & $17(12,2 \%)$ \\
\hline OPINATIVO & $29(20,8)$ \\
\hline
\end{tabular}

$\mathrm{Na}$ etapa de edição, identificamos em que editoria as 139 matérias analisadas se encontram (ver Tabela 4). Ainda de maneira mutuamente excludente - como nas tabelas anteriores -, observamos que a editoria de política se faz mais presente, em 105 das 139 postagens, equivalente a 75,5\%. Em seguida, temos a seção arte-cultura, com 14,3\% (20 matérias). As outras editorias possuem números ínfimos, com cada uma tendo menos de $5 \%$, chegando até a nulidade total na editoria classificados-propaganda. 
A partir dos números, entendemos por qual razão o Blog do Noblat é reconhecido como um blog político, embora não seja o único assunto abordado no dispositivo. A editoria arte-cultura demonstra também uma importância, sobretudo por causa da existência de algumas rubricas específicas: "Bom Dia”; "Música do Dia”; "Obra prima do dia"; "Hora do recreio"; "Poema da noite". A única rubrica que não se encaixa na editoria arte-cultura é a "Agenda de Lula", de política.

Tabela 4 - Editorias em que as postagens se encontram.

\begin{tabular}{|c|c|}
\hline ARTE-CULTURA & $20(14,3 \%)$ \\
\hline CIÊNCIA-EDUCAÇÃO & $1(0,7 \%)$ \\
\hline COMPORTAMENTO-COLUNA & $2(1,4 \%)$ \\
\hline CLASSIFICADOS-PROPAGANDA & 0 \\
\hline ESPORTE & $1(0,7 \%)$ \\
\hline ECONOMIA & $1(0,7 \%)$ \\
\hline INFORMÁTICA-TECNOLOGIA & $1(0,7 \%)$ \\
\hline POLICIAL & $3(2,2 \%)$ \\
\hline POLÍTICA & $105(75,5 \%)$ \\
\hline SOCIAL-SERVIÇO & $5(3,6 \%)$ \\
\hline
\end{tabular}

A próxima etapa não foi analisada com mútua exclusão. Consequentemente, uma postagem pode possuir mais de um aspecto listado. Nesta etapa, buscamos verificar os formatos midiáticos utilizados: texto (sozinho e com outro formato); link (para o local original da postagem copiada e para um conteúdo diferente do que foi veiculado); vídeo; áudio; imagem; infográfico-animação (ver Tabela 5). As matérias que trazem apenas textos são predominantes: 67 , proporcional a 48,2\% dos 139 materiais estudados. Os conteúdos que dispõem de texto e mais outro formato corresponde a 59 , isto é, $42,4 \%$. Os links que levam o leitor à postagem original (quando copiadas) se fazem presentes em 35 dos conteúdos, ou seja, 25,2\% de todo 
produto examinado. Os links para um conteúdo inédito estão apenas em 12 matérias, equivalente a 8,6\%. Número igual é percebido nos materiais que trazem vídeo. Áudio e infográfico-animação não foram postos em nenhuma das 139 matérias. As imagens, por sua vez, podem ser percebidas em 27 (19,4\%) das postagens.

Tabela 5 - Formatos midiáticos disponibilizados nas postagens.

\begin{tabular}{|c|c|c|}
\hline & APENAS TEXTO & $67(48,2 \%)$ \\
\hline & TEXTO E OUTRO & $59(42,4 \%)$ \\
\hline & LINK PARA ORIGINAL & $35(25,2 \%)$ \\
\hline & LINK PARA OUTRO & $12(8,6 \%)$ \\
\hline & VÍDEO & $12(8,6 \%)$ \\
\hline & ÁUDIO & 0 \\
\hline & IMAGEM & $27(19,4 \%)$ \\
\hline & INFOGRÁFICO-ANIMAÇÃO & 0 \\
\hline
\end{tabular}

Apesar de o blog receber o nome do jornalista Ricardo Noblat e este possuir o maior número de postagens, o colaborador Severino Motta produz mais conteúdo inédito, restando a Noblat a função de divulgador, caçador de material no ciberespaço. Portanto, apesar de o dispositivo ter relação direta com o jornalista, quem torna o blog menos em um espaço de sumário de conteúdo da internet é o seu principal colaborador. A equivalência entre postagens copiadas $(50,3 \%)$ e inéditas $(49,6 \%)$ esclarece um pouco o modo como o administrador do blog utiliza o dispositivo. Ao invés de expor matérias próprias, atém-se à divulgação maciça de informaçôes, mesmo que estas tenham sido divulgadas por grandes empresas, aliás, ele privilegia conteúdos advindos destas. Percebemos, por exemplo, que as três fontes mais recorrentes são $O$ Globo $(51,4 \%)$, Folha $(11,4 \%)$ e 
Estadão (11,4\%), grandes conglomerados de comunicação, que correspondem a quase todos os materiais copiados, isto é, 74,2\% (em números, 52 matérias de um total de 70).

A hipótese da agenda-setting prevalece no blog estudado, quando comprovamos que, além das grandes empresas, a fonte responsável pela metade das matérias copiadas é $O$ Globo, grupo ao qual o Blog do Noblat é vinculado. Deste modo, embora pareça ser um espaço livre e sem crivos, podemos inferir que uma força empresarial e institucional se faz presente no blog do jornalista, tendo em vista o lugar de destaque recebido por um meio do mesmo grupo que o blogueiro trabalha. A visão do pesquisador José Pinho (2003, p. 105) é de que cada divulgador de informação deve ter sua própria lista de sites de referência. Ainda que concordemos com Pinho, seria interessante que o Blog do Noblat olhasse além das fontes oficiais, dos meios já consagrados, pois estes já possuem bastante divulgação e penetrabilidade.

Quando foram analisados os gêneros jornalísticos, percebemos que o informativo é predominante nas postagens - com 66,9\% -, seguido, respectivamente, do opinativo $(20,8 \%)$ e do interpretativo $(12,2 \%)$. Deste modo, quebra-se a concepção do blog como espaço para divulgação da opinião. Esses números podem ser apenas um reflexo de um blog jornalístico ou organizacional, segundo classificação de Primo (2008a, 2008b), tornando óbvio que o blog deixou de ser apenas um diário.

Com a verificação das editorias, percebemos que o Blog do Noblat tem motivo para ser considerado um blog político, pois esta seção equivale a $75,5 \%$ das postagens analisadas. Ainda assim, percebemos o interesse do criador do blog pela arte e cultura, editoria que é recorrente em 14,3\% das matérias. Ainda na parte de edição, no que concerne aos formatos midiáticos, percebemos que o texto é predominante, estando presente em 90,6\% das postagens. Contudo, em mais da metade das matérias $(53,2 \%)$ só ele é encontrado, enquanto em $46,8 \%$ o texto é disposto com outro formato, como vídeo, imagem e 
link. Desta maneira, percebemos que o Blog do Noblat não aproveita a possibilidade multimidiática oferecida pela web. Outro fator não tão explorado pelo blog é a utilização de links para a expansão do assunto abordado. Dos $47(33,8 \%)$ links encontrados nas 139 postagens, apenas $25,5 \%$ (12 matérias) possuem links para conteúdo inédito, expandindo o material inicial, enquanto 74,5\% (35 matérias) dos links direcionam para o original das postagens que foram copiadas.

\section{Referências}

ERBOLATO, Mário. Técnicas de codificação em Jornalismo. São Paulo: Ática, 2006.

GREEN-PEDERSEN, Christoffer; MORTENSEN, Peter. Who sets the agenda and who responds to it in the Danish parliament? A new model of issue competition and agenda-setting. European Journal of Political Research. v. 49, p. 257-281, 2010,

LAGE, Nilson. Linguagem jornalística. 8. ed. São Paulo: Ática, 2006.

LOPEZ-ESCOBAR, Esteban; LLAMAS, Juan Pablo; MCCOMBS, Maxwell; LENNON, Federico. Two Levels of Agenda Setting Among Advertising and News in the 1995 Spanish Elections. Political Communication. v. 15, p. 225-238, 1998, MAZARR, Michael. The Iraq War and Agenda Setting. Foreign Policy Analysis. v. 3, p. 1-23, 2007.

McCOMBS, Maxwell. A Look at Agenda-setting: past, present and future. Journalism Studies. v. 6, n. 4, p. 543-557, 2005.

McCOMBS, Maxwell; SHAW, Donald. The agenda-setting function of mass media. In: The Public Opinion Quarterly. v. 36, n. 2, p. 176-187, 1972.

McCOMBS, Maxwell; LOPEZ-ESCOBAR, Esteban; LLAMAS, Juan Pablo. Setting the agenda of attributes in the 1996 Spanish general election. Journal of Communication. v. 50, n. 2, p. 77-92, 2000.

MEDINA, Cremilda. Notícia: um produto à venda. Jornalismo na sociedade urbana e industrial. 2. ed. São Paulo: Summus, 1988.

PENA, Felipe. Teoria do Jornalismo. São Paulo: Contexto, 2008. 
PINHO, José. Jornalismo na internet: planejamento e produção da informação online. São Paulo: Summus, 2003.

PRIMO, Alex. Blogs e seus gêneros: Avaliação estatística dos 50 blogs mais populares em língua portuguesa. In: CONGRESSO BRASILEIRO DE CIÊNCIAS DA COMUNICAÇÃO - INTERCOM. 31. 2008a, Natal. Anais... Disponível em: $<$ http://intercom.org.br/papers/nacionais/2008/resumos/R3-1199-1.pdf>. Acesso em: 27 de julho de 2009.

Os blogs não são diários pessoais online: matriz para tipificação da blogosfera. Revista FAMECOS. n. 36, ago., p. 122-128, 2008b,. Disponível em: <http:// revcom.portcom.intercom.org.br/index.php/famecos/article/download/5484/4979>. Acesso em: 27 de julho de 2009.

SOUSA, Jorge. As notícias e os seus efeitos. Portugal: MinervaCoimbra, 2000.

TAKESHITA, Toshio. Current Critical Problems in Agenda-Setting Research. International Journal of Public Opinion Research, 18, p. 275-296, 2006.

TRÄSEL, Marcelo. A vitória de Pirro dos blogs: ubiqüidade e dispersão conceitual na web. In: AMARAL, Adriana; RECUERO, Recuero; MONTARDO, Sandra. Blogs.Com: estudos sobre blogs e comunicação. São Paulo: Momento Editorial, 2009, p. 93-108. Disponível em: <http://www.sobreblogs.com.br/blogfinal.pdf>. Acesso em: 24 abr. 2009.

WARD, Mike. Jornalismo online. São Paulo: Roca, 2006.

WOLF, Mauro. Teorias das comunicações de massa. 2. ed. São Paulo: Martins Fontes, 2005.

WOODLY, Deva. New competencies in democratic communication? Blogs, agenda setting and political participation. Public Choice, 134, p. 109-123, 2008. 